\title{
A chrome-free combination tanning strategy: based on silicic acid and plant tannin
}

\author{
Zetian Zhang ${ }^{1,2}$, Yang Liu' ${ }^{1,2}$, Junchao Wang ${ }^{1,2}$, Taoling Xie ${ }^{1,2}$, Liying Sun ${ }^{1,2}$ and Zhengjun Li $i^{1,2^{*}}$
}

\begin{abstract}
Silicic acid, commonly derived from cheap and easily available sodium silicate, has recently received great attention for application in leather industry to produce ecological leather with a cleaner approach. However, leather tanned with silicic acid alone is poor in storage stability, which limits its practical application in leather production. In this work, a new environment-friendly combination tannage based on silicic acid and plant tannin was developed to address this issue along with improving the comprehensive performances of leather. The obtained leather was characterized by scanning electron microscopy, Fourier transform infrared spectroscopy, X-ray photoelectron spectroscopy and so on. The results showed that compared with leather tanned with silicic acid alone, the leather tanned with this combination method possessed improved thermal stability, enhanced mechanical properties, acceptable softness, appropriate hydrophilicity, and especially enhanced storage stability. More importantly, the combination tanned leather with 1:1 of the mass ratio of silicic acid to vegetable tannin (composed of valonea extract and mimosa extract with the same weight) had more prominent comprehensive performances. In addition, the results demonstrated that hydrogen bonding played an important role in the combination tanning process. Furthermore, the hydrogen bonds generated between phenolic hydroxyl groups of polyphenols with silicon hydroxyl groups of silicic acid molecules inhibited the excessive condensation of $\mathrm{Si}-\mathrm{OH}$ groups between themselves. Subsequently, the assessment of environmental impact revealed the value of $\mathrm{BOD}_{5} / \mathrm{COD}$ of the wastewater produced in this combination tanning process is more than 0.3 , indicating the chrome-free combination tannage based on silicic acid and plant tannin was an environment-friendly tanning technology. These findings therefore indicated that a new chrome-free tanning method with silicon and biomass materials as main tanning agents has potential practical application prospect in leather production.
\end{abstract}

Keywords: Silicic acid, Plant tannin, Chrome-free tannage, Storage stability, Environment-friendly

\section{Introduction}

The leather industry plays an important role in our daily life. And as an important industrial material product, leather is widely used in many fields, including shoes, clothing and furniture upholstery [1,2]. Tanning is a meaningful process in the leather industry, which improves thermal stability, mechanical properties and

\footnotetext{
* Correspondence: lizhengjun@scu.edu.cn

${ }^{1}$ National Engineering Research Center of Clean Technology in Leather Industry, Sichuan University, Chengdu 610065, China

${ }^{2}$ Key Laboratory of Leather Chemistry and Engineering of Ministry of Education, Sichuan University, Chengdu 610065, China
}

porosity of leather [3]. In the leather industry, basic chromium sulphate is preferred as tanning agent, mainly because of its lower cost and better reactivity with collagen fiber [4]. However, it is difficult to dispose the solid waste containing chromium generated in leather manufacturing, and chromium (III) might be converted into chromium (VI), which can cause harm to human skin and lead to some other diseases [5-9]. In addition, it would take decades or even hundreds of years for chrome tanned leather to be biodegraded in nature, which may cause the ecological imbalance [10].

\section{Springer Open}

(0) The Author(s). 2021 Open Access This article is licensed under a Creative Commons Attribution 4.0 International License, which permits use, sharing, adaptation, distribution and reproduction in any medium or format, as long as you give appropriate credit to the original author(s) and the source, provide a link to the Creative Commons licence, and indicate if changes were made. The images or other third party material in this article are included in the article's Creative Commons licence, unless indicated otherwise in a credit line to the material. If material is not included in the article's Creative Commons licence and your intended use is not permitted by statutory regulation or exceeds the permitted use, you will need to obtain permission directly from the copyright holder. To view a copy of this licence, visit http://creativecommons.org/licenses/by/4.0/. 
Therefore, it is imperative to develop chrome-free tanning technology.

Up to now, many chemicals for chrome-free tanning systems have been developed. As a matter of fact, traditional aldehyde tanning agents and vegetable tanning agents can be used to produce chrome-free leather. However, leather tanned with aldehyde tanned leather has the risk of releasing free formaldehyde, and vegetable tannins are not suitable for preparing light leather, which are often used in combination with other tanning agents [11]. Besides, non-chrome metal such as aluminium salt, titanium salt, and zirconium salt can also be applied to the production of chrome-free leather [1113]. Nevertheless, the obtained leather suffered from some inherent limitations such as no washability, hardness and poor organoleptic properties. Furthermore, synthetic tanning agents including amino resins and vinyl copolymers also exhibited unsatisfactory tanning effects like low shrinkage temperature, insufficient fiber dispersion and poor mechanical properties, when they were used as main tanning agent. It is worth noting that in recent years, some organic tanning agents based on biomass, such as starch, chitosan and cellulose, especially their derivatives, have been explored and used in the main tanning stage, combined with other chromefree tanning agents, and showed very good prospect [14-16]. But there are still lots of issues that need to be addressed. Nevertheless, it can be found that the combination tanning method using different tanning agents with different characteristics is an effective method and achievable strategy.

In recent years, with the development of silicon chemistry and the progress of nanotechnology, the application of silicon-containing materials in chrome-free tanning systems has attracted increasing attention. For example, an environmentally-friendly tanning process based on nano-silica was explored, and it was reported that the obtained leather had shrinkage temperature as high as $98.2^{\circ} \mathrm{C}$ [17]. In addition, the leather tanned by using Laponite nano-clay combined with tetrakis (hydroxymethyl) phosphonium sulfate exhibited good physical performance [18]. Interestingly, zeology, a chrome-free, heavy metal-free and aldehyde-free tanning agent based on zeolite, was developed by Smit \& Zoon Company, and reported that the tanned leather by zeology had lightfastness, light color, heat resistance and good physical properties. In addition, our team found that silane glycidoxypropyltrimethoxysilane (GPTMS) can increase the porosity of the skin collagen fiber matrix and make the pore distribution more uniform [19]. Especially, we recently developed a new tanning method, which is based on silicic acid derived from sodium silicate and silane containing epoxy group (GPTMS), can make the Ts value of the leather reach $88^{\circ} \mathrm{C}$, and improve its storage stability [20]. However, comprehensive properties of the leather are still insufficient, especially lacking enough softness and hydrophilicity, so it should be improved for further practical application. Therefore, it is still an impending requirement for leather industry to find an efficient chrome-free tanning technology that can not only alleviate the impact on the environment, accelerate sustainable development, but also endow leather with acceptable comprehensive performances for practical application.

As for vegetable tanning agents, there are many multipoint hydrogen bonding between phenolic hydroxyl groups and the active groups (e. g. $-\mathrm{NH}_{2},-\mathrm{COOH}$, $-\mathrm{OH}$ ) of collagen fiber, as well as other chemical bonds such as ionic bond, covalent bond and hydrophobic interaction. As a result, their synergistic effect improves the performance of the leather [21]. Importantly, vegetable tanning agents are usually used in combination with other chrome-free tanning agents to obtain unique effects and make distinctive leather [22]. A fascinating method of combining vegetable tanning agent and silicon materials has attracted great attention. For example, the leather produced by combination tanning of tannic acid, aluminum sulfate and sodium metasilicate can achieve a satisfactory shrinkage temperature (about $95^{\circ} \mathrm{C}$ ), and improved softness and fluffiness [23]. Through tanning with a combination of tannic acid and laponite nano-clay, the obtained leather was in possession of Ts exceeding $86^{\circ} \mathrm{C}$, and the laponite showed a good tanning effect, which can combine with collagen fiber tightly and evenly [24]. In our previous work, we found that hydrogen bonds between silicon hydroxyl groups of silicic acid and amino groups of collagen fiber play an important role in tanning process, which is consistent with vegetable tanning method to some extent [20]. Therefore, it can be deduced that the combination tanning of silicic acid with vegetable tanning agent is an effective tanning method. On the one hand, the phenolic hydroxyls of vegetable tanning agent may form hydrogen bonding with silicon hydroxyls, probably inhibiting further condensation of $\mathrm{Si}-\mathrm{OH}$ themselves during storage, and thus improving the softness and hydrophilicity of the tanned leather. On the other hand, hydrogencontaining active groups of these two tanning agents can also form hydrogen bonds with collagen fibers. As a result, a synergistic effect took place. Furthermore, due to the existence of covalent crosslinking structure of Si-O$\mathrm{Si}$ network, the silicon-containing materials employed might play a positive role in the thermal stability and tensile strength of the tanned leather. To the best of our knowledge, the tanning technology based on the combination of silicic acid and plant tannin is a tanning method with great development potential, but there are few reports in this field. 
In this study, a chrome-free combination tanning method based on vegetable tanning agent and silicic acid was proposed. Here, there is no strict difference in the expression of vegetable tanning agent, plant tannin and plant polyphenols. Thermal properties of the as-prepared leather were characterized by Ts, differential scanning calorimetry (DSC) and thermal gravimetric analysis (TGA). Softness, thickening rate and mechanical strength of the leather were also recorded. Besides, the chemical structure and the microstructure were further investigated by Fourier transformed infrared spectroscopy (FT-IR), X-ray photoelectron spectroscopy (XPS), and scanning electron microscopy (SEM). At last, by testing chemical oxygen demand (COD), five-day biological oxygen demand $\left(\mathrm{BOD}_{5}\right)$, total solids (TS), total dissolved solids (TDS), and total suspended solids (TSS) content of tannery wastewater, the environmental impact assessment was realized. This study reported an environmental-friendly and effective combination tanning technology, which would not only further expand the application of silicon materials in leather tanning, but also provide exciting opportunities to the sustainable development of the leather industry.

\section{Experimental}

\subsection{Materials}

Pickled goatskin, prepared by ourselves according to the conventional method [25], was utilized in tanning experiments. Silicic acid, derived from sodium silicate (provided from Kelong Reagent Co. Ltd. (Chengdu, China)), was prepared by ourselves in accordance with our previous article [26]. Firstly, sodium silicate solution with a concentration of $10 \%$ was prepared. Then it was poured into sulfuric acid solution (50\%) according to the stoichiometric ratio of 1: 1.05 . And the solution of silicic acid was stirred well for later use. Valonea extract (a hydrolysable tannin) and mimosa extract (a condensed tannin) were purchased from Sichuan Dowell Science and Technology Inc. (Chengdu, China). Sulfuric acid, sodium silicate, sodium hydrogen carbonate, and sodium chloride were provided by Kelong Reagent Co. Ltd. (Chengdu, China), and all the above reagents are analytical-reagent grade.

\subsection{Tanning process}

In our previous work [20], the better dosage of tanning agent was determined to be $15 \mathrm{wt} \%$ of pickled skin, which is the total amount of tanning agent used in this work. The tanning process was shown in Table 1. In detail, the skin was immersed in $100 \%$ pickled float with a $\mathrm{pH}$ value of $2.0-2.5$, and the float was rotated for $0.5 \mathrm{~h}$. Subsequently, silicic acid solution was added to the drum, and kept rotating for $5.0 \mathrm{~h}$. Then, the $\mathrm{pH}$ value was adjusted to $4.0-4.5$ by adding an appropriate amount of $\mathrm{NaHCO}_{3}$ within about $1.0 \mathrm{~h}$. Thereafter, the vegetable tannin (composed of valonea extract and mimosa extract with the same weight) was added and tanned for $2.0 \mathrm{~h}$, then the temperature was adjusted to $40^{\circ} \mathrm{C}$ by adding the same amount of water as the pickled skin, and further tanning for $2.0 \mathrm{~h}$, then stopped and kept overnight. The next morning, the drum was further turned for $2.0 \mathrm{~h}$, then the float was drained and the leather was washed and free dried. Prepared leather samples were represented by $\mathrm{S}-\mathrm{V}-1, \mathrm{~S}-\mathrm{V}-2$, and $\mathrm{S}-\mathrm{V}-3$ according to the mass ratio of silicic acid to vegetable tannin, that is, 2:1, 1:1, and 1:2 respectively. In addition, the sample tanned by silicic acid alone was recorded as $\mathrm{SA}$, and the leather tanned by vegetable tanning agent alone was named VA. The codes and formula of the leathers were shown in Table S1 in supplementary information. In addition, the appearance and color of the SA, $\mathrm{S}-\mathrm{V}-2$, and VA leather samples were shown in Fig. S1 in supplementary information. Moreover, in order to improve the accuracy of the experimental results, each tanning process was repeated at least three times by using different goatskin samples.

Table 1 Silicic acid-vegetable tannin combination tanning process

\begin{tabular}{|c|c|c|c|c|}
\hline Process & Material & Dosage(\%) & Time(h) & Remark \\
\hline \multirow[t]{3}{*}{ Pickling } & Water & 100 & & \\
\hline & $\mathrm{NaCl}$ & 8 & & \\
\hline & Formic acid & 1.2 & 0.5 & $\mathrm{pH} 2.0-2.5$ \\
\hline \multirow[t]{2}{*}{ Silicic acid tanning } & Silicic acid (based on amount of $\mathrm{SiO}_{2}$ ) & $x^{a}$ & 5.0 & \\
\hline & $\mathrm{NaHCO}_{3}$ & 1.5 & 1.0 & 20 times dilution \\
\hline \multicolumn{5}{|c|}{ Adjust the $\mathrm{pH}$ of tanning solution to $4.0 \sim 4.5$} \\
\hline \multirow[t]{2}{*}{ Vegetable tanning } & Vegetable tannin & $y^{a}$ & 2.0 & \\
\hline & Water & 100 & 2.0 & $40^{\circ} \mathrm{C}$ \\
\hline \multicolumn{5}{|l|}{ Overnight } \\
\hline \multicolumn{5}{|c|}{ Rotation for $2.0 \mathrm{~h}$, then water washing, taking out and drying } \\
\hline
\end{tabular}




\subsection{Characterization}

\subsubsection{Testing of hydrothermal stability}

Hydrothermal stability of the leather was tested under the water bath according to ISO 3380-2015 by a shrinkage tester (MSW-YD4). The specific mold was used to cut the samples into rectangular $(50 \mathrm{~mm} \times 3$ $\mathrm{mm})$. Subsequently, the samples were heated in water at the rate of $2{ }^{\circ} \mathrm{C} / \mathrm{min}$. Form every sample at least five tests were recorded and the average was calculated [27].

\subsubsection{Differential scanning calorimeter (DSC)}

DSC-200PC (Netzsch, Germany) was used to characterize the thermal denaturation temperature of the leather samples [18]. Briefly, the weight of the freeze-dried samples at different storage time was recorded, and was heated from $20^{\circ} \mathrm{C}$ to $160^{\circ} \mathrm{C}$ under nitrogen protection and the heating rate was $5^{\circ} \mathrm{C} / \mathrm{min}$. Every sample was measured repeatedly at least five times.

\subsubsection{Thermogravimetric analysis (TGA)}

Thermal stability of the sample was also measured by TG 209 (Netzsch, Germany). The freeze-dried sample was cut into appropriate pieces and the weight was also recorded. The heat temperature was from 50 to $800{ }^{\circ} \mathrm{C}$ according to the rate of $10^{\circ} \mathrm{C} / \mathrm{min}$ under nitrogen protection. Each sample was carried out by five independent measurements $[28,29]$.

\subsubsection{Mechanical tests}

The testing of the mechanical of the samples was according to the standard procedure (ISO 3376-2020) and more details were introduced in supporting material S1 $[30,31]$. The mechanical properties of $S-\mathrm{V}-1, \mathrm{~S}-\mathrm{V}-2$, and $\mathrm{S}-\mathrm{V}-3$ were compared with $\mathrm{VA}$ and $\mathrm{SA}$ reference samples.

\subsubsection{Thickening rate}

Thickening rate of leather can reflect the filling performance of the tanning agent, which is related to the change of leather pore structure. Before tanning, thickness of leather was measured by a thickness gauge according to ISO 2589:2016. Every sample was chosen from five locations to measure, and the mean value of the results was calculated and recorded as $d_{0}(\mathrm{~mm})$. Then, after tanning, the thickness of leather in the same position was also calculated and recorded as $d_{1}(\mathrm{~mm})$. Subsequently, the thickening rate $\left(T_{r}\right)$ can be calculated according to the following formula (1) [32, 33].

$$
T_{r}=\frac{d_{1}-d_{0}}{d_{0}} \times 100 \%
$$

\subsubsection{Softness}

Softness is one of the important indices to examine the organoleptic property of leather. ST-300 leather softness tester equipped with a $20 \mathrm{~mm}$ ring was used to determine the softness of the samples according to the standard of ISO 17235-2015. The details of the measure method was shown in supporting materials S2 [34, 35].

\subsubsection{Water absorption}

Hydrophilicity of leather was determined by testing water absorption [36]. Briefly, the leather was cut into small pieces $\sim 1 \times 1 \mathrm{~cm}$, and weighted as $\mathrm{W}_{0}$. Then put it in a beaker, add appropriate amount of water, and take it out at $30 \mathrm{~min}, 60 \mathrm{~min}, 90 \mathrm{~min}, 150 \mathrm{~min}$ and $210 \mathrm{~min}$, respectively. Then, wipe off the adsorbed water on the sample surface with filter paper, and the weight was recorded as $\mathrm{W}_{\mathrm{t}}$. The water absorption was calculated according to formula (2). Every sample was measured by five times, and an average value was calculated.

$$
\text { Water absorption }=\frac{W_{t}-W_{0}}{W_{0}} \times 100 \%
$$

\subsubsection{Contact angle}

Contact Angle System OCA was employed to determine surface hydrophilicity of the leather. Specially, the leather was cut into suitable size and fixed on the glass slide with grain face up before the measurement system was started. Then the photo was taken and the contact angle of the leather surface was calculated. The result represents the average value of at least five measurements [36].

\subsubsection{Scanning electron microscope (SEM)}

The leather samples obtained were cut into small pieces of proper size. And then they were dried in the freeze dryer (SCIENTZ-10 N, China) at $-60^{\circ} \mathrm{C}$, after they were frozen at the refrigerator at $-30{ }^{\circ} \mathrm{C}$ overnight. Subsequently, the fracture section of the samples was observed by scanning electron microscopy (JEOL, Japan). Their pore size distribution ere measured by nano-measure software [26].

\subsubsection{Fourier transform infrared spectroscopy (FT-IR)}

The chemical structure of the tanned leather was measured by the Fourier transform infrared spectroscopy (FT-IR) at the range of $400-4000 \mathrm{~cm}^{-1}$. Briefly, the tanned leather sample was freeze-dried, then ground into powder, and then mixed with potassium bromide $(\mathrm{KBr})$ powder. Measurement was performed with a 
resolution of $4 \mathrm{~cm}^{-1}$, and the spectra was stored in the computer and analyzed [37].

\subsubsection{X-ray photoelectron spectroscopy (XPS)}

The Escalab-220i XPS (Kratos, Japan) was used to measure the element content of the samples. Particularly, the high-resolution XPS spectra of the N1s, O1s, C1s, and $\mathrm{Si} 2 \mathrm{p}$ was measured respectively at energy $20 \mathrm{eV}$. And the further analysis was carried out at the Service Physics ESCAVB data reduction software [26].

\subsubsection{Evaluation of tanning waste water}

Biochemical Oxygen Demand $\left(\mathrm{BOD}_{5}\right)$ and Chemical Oxygen Demand (COD) of the waste water were tested reference to EN 1899:2003 and ISO 6060:1996, respectively. Furthermore, according to EN 872:2005 the Total Dissolved Solids (TDS) was measured, and Total Solid (TS), and Total Suspended Solid (TSS) of the waste water were also calculated [38, 39].

\section{Results and discussion}

\subsection{Thermal stability}

Some post-tanning treatment processes of leather, such as drying, plating, ironing, embossing, and especially shaving, need to set appropriate temperature to obtain leather with good comprehensive properties. Thus, thermal stability is an important index to judge the quality of leather. In addition, in order to explore storage stability of the leather, their shrinkage temperature, thermal denaturation temperature and thermal decomposition temperature after storage for $0,1,3$, and 5 days were measured and analyzed.

\subsubsection{Shrinkage temperature}

Table 2 shows the Ts values of different leather samples stored for $0,1,3$, and 5 days. As it is known, the Ts of the leather tanned by silicic acid alone will change obviously during storage. It can be found here that the Ts of the SA sample did increase by about $23^{\circ} \mathrm{C}$, from $\sim 68^{\circ} \mathrm{C}$ to $\sim 91^{\circ} \mathrm{C}$ from 0 to 5 days, which may be due to the continuous condensation of $\mathrm{Si}-\mathrm{OH}$ between themselves during the storage process. However, this situation changed when the vegetable tanning agent was added in combination with silicic acid. The change degree of the Ts of S-V-1 was milder than SA, about $8^{\circ} \mathrm{C}$. While the Ts of S-V-2 or S-V-3 is nearly stable, within the range of $80-83^{\circ} \mathrm{C}$. Interestingly, the Ts of VA sample was also slightly different, only about $3^{\circ} \mathrm{C}$, ranging from $\sim 78^{\circ} \mathrm{C}$ to $\sim 81^{\circ} \mathrm{C}$. These results indicated that the addition of vegetable tanning agent seems to be able to control the Ts value of silicic acid tanned leather; that is to say, to make the combination tanned leather more stable in hydrothermal shrinkage. Furthermore, the more the vegetable tanning agent was added, the slighter change of the Ts of the leather. This phenomenon is likely to be attributed to the more incorporated phenolic hydroxyl groups, and more hydrogen bonds generated between phenolic hydroxyl with silicon hydroxyl groups, which thereby impeding the further condensation of $\mathrm{Si}-\mathrm{OH}$ themselves. Moreover, on the 0 day, the Ts of S-V-2 and $\mathrm{S}-\mathrm{V}-3$ were both greater than that of SA or VA, which indicated the synergistic effect between the two tanning agents.

\subsubsection{Thermal denaturation temperature}

DSC was used to measure the thermal stability of the leather. DSC curves can reflect the denaturation degree of the leather, which is related to the degree of crosslinking and crystalline structure of the collagen fiber [40]. Figure 1 shows that when the tanning process was just accomplished, the denaturation temperature of the SA sample was low, $\sim 68.4{ }^{\circ} \mathrm{C}$; while it increased to $98.5^{\circ} \mathrm{C}$ after 5 days. This may be related to dehydration and condensation of silicon hydroxyls themselves, and hence more Si-O-Si network structure formed during the storage period, which improves the thermal stability of leather [41]. With the increase of the amount of vegetable tanning agent, the change range of the denaturation temperature decreased. The denaturation temperature of S-V-1 increased from $\sim 75.1{ }^{\circ} \mathrm{C}$ to $\sim 92.8^{\circ} \mathrm{C}$, and that of $\mathrm{S}-\mathrm{V}-2$ and S-V-3 sample were in the range of 80.4$85.0^{\circ} \mathrm{C}$ and $73.8-79.2^{\circ} \mathrm{C}$, respectively. The lower thermal denaturation temperature of S-V-3 in the 0 day might be ascribed to the more phenolic hydroxyl groups, greatly restricting the condensation of $\mathrm{Si}-\mathrm{OH}$. It should be noted that, the order of thermal denaturation temperature values from large to small is $\mathrm{SA}, \mathrm{S}-\mathrm{V}-1, \mathrm{~S}$ $\mathrm{V}-2$ and $\mathrm{S}-\mathrm{V}-3$ after storage for 5 days. This phenomenon might be clearly related to the formation of hydrogen bonds between $\mathrm{Si}-\mathrm{OH}$ and phenolic hydroxyl groups, which restrained the dehydration and condensation of $\mathrm{Si}-\mathrm{OH}$ groups themselves, and as a

Table 2 Shrinkage temperature of the samples

\begin{tabular}{llllll}
\hline Storage time (d) & SA & S-V-1 & S-V-2 & S-V-3 & VA \\
\hline 0 & $68.4 \pm 3.93$ & $75.8 \pm 0.48$ & $79.2 \pm 0.79$ & $80.2 \pm 0.50$ & $77.9 \pm 0.52$ \\
1 & $72.2 \pm 1.15$ & $78.2 \pm 0.75$ & $80.8 \pm 0.23$ & $82.0 \pm 0.24$ & $79.1 \pm 0.65$ \\
3 & $83.4 \pm 1.56$ & $81.4 \pm 0.53$ & $82.3 \pm 0.87$ & $82.1 \pm 0.38$ & $80.6 \pm 0.41$ \\
5 & $91.2 \pm 1.32$ & $83.0 \pm 0.75$ & $82.9 \pm 0.44$ & $81.9 \pm 0.55$ & $81.1 \pm 0.94$ \\
\hline
\end{tabular}



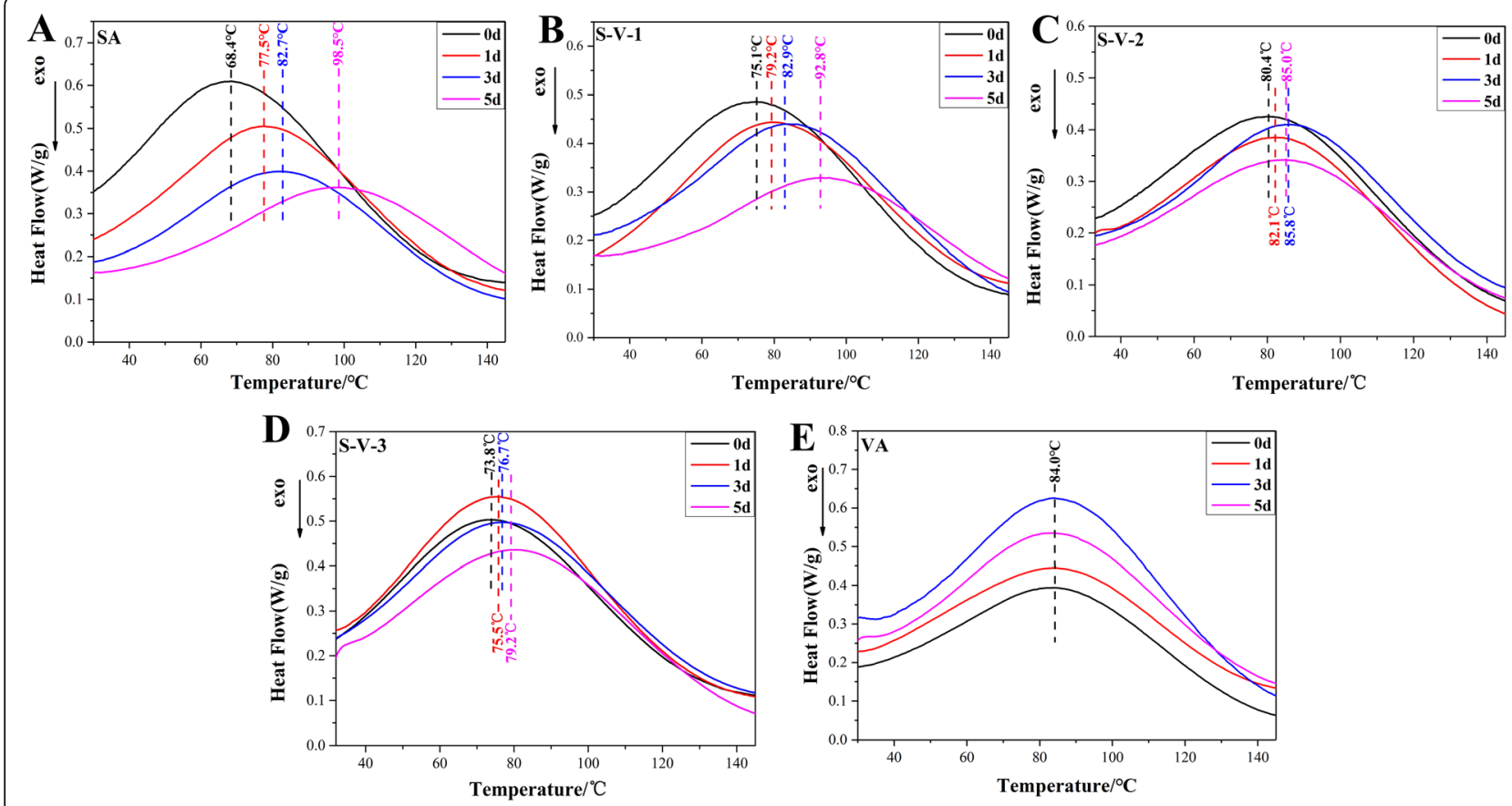

Fig. 1 DSC curves of SA (a), S-V-1 (b), S-V-2 (c), S-V-3 (d) and VA (e) at different storage time

Table 3 Weight loss rate and $T_{\max }$ of the samples at different storage time

\begin{tabular}{|c|c|c|c|c|}
\hline Sample & & $\mathrm{T}_{\max }\left({ }^{\circ} \mathrm{C}\right)$ & Second stage weight loss rate(\%) & Total weight loss rate(\%) \\
\hline \multirow[t]{4}{*}{$\overline{S A}$} & 0 & 343.5 & 49.89 & 68.60 \\
\hline & 1 & 345.4 & 48.81 & 66.89 \\
\hline & 3 & 354.9 & 49.49 & 65.52 \\
\hline & 5 & 356.9 & 46.07 & 59.70 \\
\hline \multirow[t]{4}{*}{$S-V-1$} & 0 & 336.9 & 54.76 & 75.64 \\
\hline & 1 & 340.1 & 52.09 & 70.69 \\
\hline & 3 & 345.9 & 51.71 & 69.17 \\
\hline & 5 & 347.0 & 51.71 & 68.03 \\
\hline \multirow[t]{4}{*}{$S-V-2$} & 0 & 344.1 & 47.93 & 68.36 \\
\hline & 1 & 344.9 & 48.63 & 65.97 \\
\hline & 3 & 344.8 & 49.99 & 64.60 \\
\hline & 5 & 345.1 & 48.62 & 63.57 \\
\hline \multirow[t]{4}{*}{$S-V-3$} & 0 & 335.2 & 53.47 & 71.77 \\
\hline & 1 & 335.4 & 53.81 & 71.01 \\
\hline & 3 & 335.4 & 53.81 & 70.25 \\
\hline & 5 & 335.9 & 52.23 & 69.11 \\
\hline \multirow[t]{4}{*}{ VA } & 0 & 311.9 & 55.67 & 79.70 \\
\hline & 1 & 312.1 & 56.04 & 78.18 \\
\hline & 3 & 311.8 & 54.84 & 76.28 \\
\hline & 5 & 312.2 & 57.57 & 73.24 \\
\hline
\end{tabular}


result the formation of $\mathrm{Si}-\mathrm{O}-\mathrm{Si}$ rigid structure was reduced. Not surprisingly, the denaturation temperature of the VA sample did not seem to change during storage, almost at $\sim 84.0^{\circ} \mathrm{C}$, which is also in good agreement with previous reports in the literature $[42,43]$.

\subsubsection{Thermal decomposition temperature}

Thermal stability of leather was also analyzed by TGA. The TGA and DTG curves of representative samples were shown in Fig. S2 in supplementary information, and the corresponding weight loss rate and maximum thermal weight loss temperature $\left(\mathrm{T}_{\max }\right)$ were shown in Table 3. The initial stage of thermal weight loss within $150{ }^{\circ} \mathrm{C}$ is mainly caused by the loss of water and other volatile small molecules inside the skin collagen fiber matrix [44]. At $200-500{ }^{\circ} \mathrm{C}$, the second weight loss stage of the sample is more obvious on the TGA curves. In this temperature range, the crosslinking between tanning agents and collagen fibers was broken. Due to the action of heating, collagen fibers and some other organic materials such as plant tannins were decomposed into small molecules and escaped, which led to the significant decline in the TG curves [28]. Therefore, the weight loss rate of VA is higher than that of others. Moreover, the third weight loss can be attributed to the evolution towards other carbonaceous substances at the $T_{\max }$ under heating, and as a result the residue was formed [45].

As for the $T_{\max }$ of the leather after 5 days storage, it was SA, S-V-1, S-V-2, S-V-3 and VA in descending order, which indicated that the $\mathrm{T}_{\max }$ of leather decreased with the increase of amount of vegetable tanning agent. This can also be explained by inhibiting condensation of $\mathrm{Si}-\mathrm{OH}$ and reducing the structure of heat-resistant and rigid Si-O-Si network, which was due to the addition of vegetable tanning agent. Compared with $\mathrm{SA}$ and $\mathrm{S}-\mathrm{V}-1$, the $\mathrm{T}_{\max }$ of $\mathrm{S}-\mathrm{V}-2$ and $\mathrm{S}-\mathrm{V}-3$ changed little during storage process, which further confirmed that adding plant polyphenols can improve the storage stability of leather.

\subsection{Physical and mechanical properties \\ 3.2.1 Softness and thickness rate}

Figure S3 shows the softness value of leather samples, that is, SA, S-V-1, S-V-2, S-V-3 and VA were $~ 5.7, \sim$ $6.0, \sim 6.4, \sim 7.0$ and $\sim 7.6$, respectively, indicating the softness of the leather increased with the increase of vegetable tanning agent dosage. This may be as a result of the formation of considerably rigid $\mathrm{Si}-\mathrm{O}-\mathrm{Si}$ network structure decreased, due to the incorporated phenolic hydroxyl groups forming hydrogen bonds with silicon hydroxyl groups, inhibiting their further condensation, and thereby rigidity of the leather decreased [46].

Thickness of leather is another important index. On the one hand, the thickness of leather is closely related to its fullness, and the change of thickness can reflect the filling effect of a tanning agent; on the other hand, different applications require different thickness of leather. Obviously, the thickness rate of the obtained leather (Fig. S4 in supplementary information) was much higher than that of traditional chrome tanned leather. In addition, the thickening rate of SA was the highest $(\sim$ $140 \%)$ and that of the VA was the smallest $(\sim 86 \%)$, among these prepared leather samples. With the increase of the amount of vegetable tanning agent, the thickness rate decreased. This result may be ascribed to the fact that silicic acid molecules would undergo condensation reaction during tanning process, to generate three-dimensional rigid $\mathrm{Si}-\mathrm{O}-\mathrm{Si}$ network structure, which is hard to deformation. However, vegetable tanning agents mainly generate hydrogen bonds, thus their filling effect is weaker than silicic acid in tanning process.

\subsubsection{Tensile strength and elongation at break}

Tensile strength test of leather can reflect the deformation of leather under external forces and the strength that the leather can bear, and it is also an important index to judge the durability and firmness of leather. In order to further explore the influence of the incorporation of vegetable tanning agent on the properties of silicic acid tanned leather, the mechanical strength and elongation at break of the samples were measured and compared. The stress-strain curves (Fig. S5 in supplementary information) shows that the SA possessed the strongest tensile strength, and the VA had the weakest strength, and further the stress of the combination tanned leather decreased with increasing amount of vegetable tanning agent. This phenomenon is closely related to the formation of the $\mathrm{Si}-\mathrm{O}-\mathrm{Si}$ rigid structure. As for the sample SA, due to the relatively large dosage of silicic acid, more Si-O-Si rigid structures were generated within the skin collagen fiber matrix; as well as more hydrogen bonding formed that help to enhance the tensile strength [42]. On the other hand, with the increase of the amount of vegetable tanning agent, the elongation at break of the samples increased significantly. This may be due to fewer formation of the Si-O-Si rigid network structure, which resulted from inhibition of the condensation of Si-OH groups by the incorporated phenolic hydroxyls. Therefore, compared with the SA sample, the elongation at break of the combination tanned leather increased.

\subsection{Water absorption and contact angle}

Hydrophilicity plays an important role in the posttanning stages of the leather and the use of leather goods. Water absorption and contact angle of the leather can reflect its hydrophilicity. Figure 2 showed that the water absorption of all samples increased sharply in the 


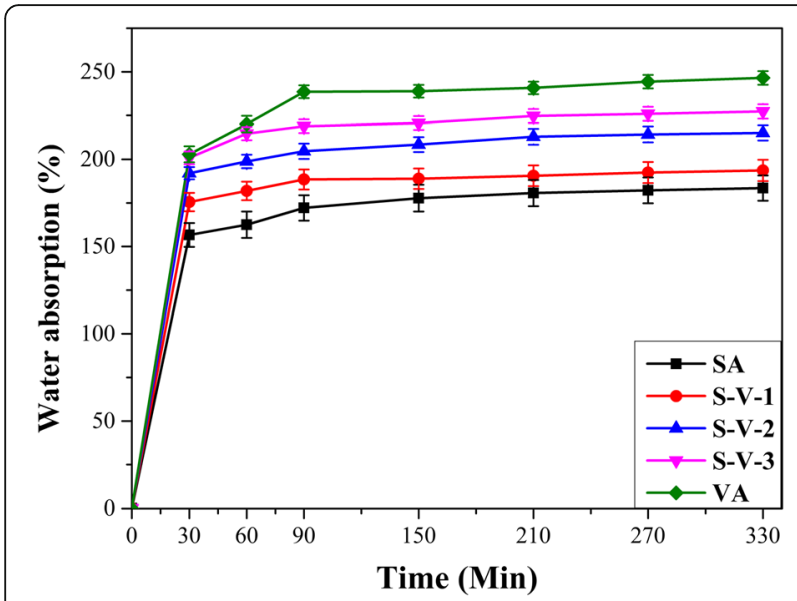

Fig. 2 Water absorption of the tanned leather

first $30 \mathrm{~min}$, among which the increase of water absorption of the VA was the highest $(\sim 36 \%)$ in the range of $30 \mathrm{~min}$ to $90 \mathrm{~min}$, while others did not exceed $20 \%$. In addition, with the increase of dosage of vegetable tanning agent, the water absorption of the leather increased. The reason is probably that, on the one hand, the phenolic hydroxyl groups in plant polyphenols have excellent hydrophilicity; and on the other hand, these phenolic hydroxyls can restrain the formation of hydrophobic Si$\mathrm{O}-\mathrm{Si}$ structure, and thus more amount of hydrophilic Si$\mathrm{OH}$ groups are remained. After $150 \mathrm{~min}$, the water absorption would almost no longer change, indicating that the equilibrium value was reached. Obviously, with the increase of amount of vegetable tanning agent, the maximum water absorption of the samples increased. These results exhibited that the combination of vegetable tanning agent and silicic acid can really improve the hydrophilicity of the tanned leather.

To further investigate surface wettability of the leather, SA, S-V-2, and VA were chosen to test the water contact angle. The smaller the contact angle, the better the hydrophilicity is [47]. As shown in Fig. S6, the VA possessed the smallest water contact angle $\left(\sim 60.6^{\circ}\right)$, and the SA had the largest one $\left(\sim 86.5^{\circ}\right)$, while S-V-2 had that of between them $\left(\sim 70.4^{\circ}\right)$. The result further indicated that the addition of vegetable tanning agent enhanced hydrophilicity of the leather, which was very consistent with the result of water absorption. Therefore, adopting the chrome-free combination tanning method based on silicic acid and vegetable tanning agent, the hydrophilicity of tanned leather would be significantly improved, which is beneficial to the subsequent processing of leather.

In a word, it was confirmed that the storage stability of leather obtained by the combination tanning method of vegetable tanning agent with silicic acid was improved significantly. With the increase of dosage of vegetable tanning agent, softness and hydrophilicity of the leather were also significantly enhanced, while the thickness rate and thermal stability of the leather decreased, but they were still acceptable. These results may be the reason that the phenolic hydroxyl groups originated from plant polyphenol molecules formed hydrogen bonding with silicon hydroxyls in silicic acid molecules, thereby inhibiting the condensation of the $\mathrm{Si}-\mathrm{OH}$ themselves. As a result, less content of rigid $\mathrm{Si}-\mathrm{O}-\mathrm{Si}$ network structure was generated, which is beneficial to improve softness of leather. To further insight into the action of plant polyphenol in the combination tanning process, the exploration was performed to the effect of vegetable tanning agent on the micromorphology and the chemical structure of the leather. Considering that the $\mathrm{S}-\mathrm{V}-2$ possesses better thermal stability, mechanical properties, hydrophilicity, fullness and softness, it was chosen to be a representative combination tanned leather for comparison with the silicic acid alone tanned leather (SA) and vegetable tanned leather (VA).

\subsection{Porous structure and micromorphology}

It is essential to research orientation and structural changes of collagen fibers in the obtained tanned leather, which directly reflects the microstructures of skin

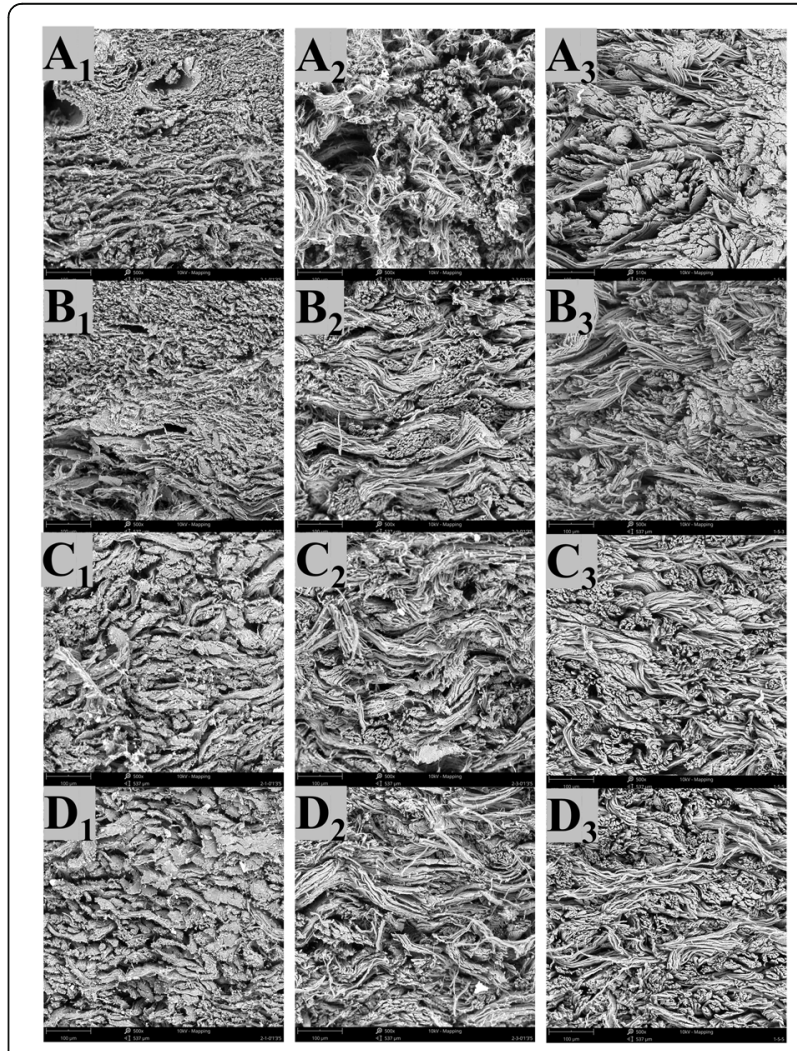

Fig. 3 SEM images of SA, S-V-2, and VA storing for $0\left(A_{1}, A_{2}, A_{3}\right), 1$ $\left(B_{1}, B_{2}, B_{3}\right), 3\left(C_{1}, C_{3}, C_{3}\right)$, and $5\left(D_{1}, D_{2}, D_{3}\right)$ days, respectively 
collagen fiber matrix. Figure 3 shows microstructure of the leather (SA, S-V-2, and VA) observed by SEM. The collagen fibers of SA (Fig. $3 \mathrm{~A}_{1}-\mathrm{D}_{1}$ ) gradually changed from relatively dispersed fibers to ordered fibrous bundles during the storage. However, the collagen fibers of $\mathrm{S}-\mathrm{V}-2$ were a relatively weak dispersion when the leather just came out of the drum (Fig. $3 \mathrm{~A}_{2}$ ); but a better fiber dispersion state was exhibited after being placed for 1 day $\left(\right.$ Fig. $3 B_{2}$ ). Despite this, the microstructure of S-V-2 changed only slightly (Fig. $3 \mathrm{~A}_{2}-\mathrm{D}_{2}$ ). As for VA, the acceptable dispersion of fibers remained basically unchanged (Fig. $3 \mathrm{~A}_{3}-\mathrm{D}_{3}$ ). To achieve a better understanding of the distinct microstructure between the obtained leathers, their pore size distribution was examined and showed in Fig. 4. Obviously, pore diameter distribution of SA changed greatly, which increased from $8-28 \mu \mathrm{m}$ (Fig. $4 \mathrm{~A}_{1}$ ) to $32-48 \mu \mathrm{m}$ (Fig. $4 \mathrm{D}_{1}$ ). However, pore size distribution of S-V-2 $(26-47 \mu \mathrm{m})$ and VA $(25-42 \mu \mathrm{m})$ remained almost unaltered. Therefore, it can be considered that the addition of vegetable tanning agent improved the dispersion uniformity and stability of collagen fibers in tanned leather. This can be ascribed to the fact that hydrogen bonding generated between phenolic hydroxyl groups of plant polyphenol and $\mathrm{Si}-\mathrm{OH}$ of silicic acid inhibited further dehydration and condensation of $\mathrm{Si}-\mathrm{OH}$ themselves during the storage period. Consequently, the results verified once again that the combination tanning of vegetable tanning agent and silicic acid was beneficial to improve the performance and the storage stability of the leather.

\subsection{Chemical structure characterization}

The chemical structure of the leather was analyzed by FT-IR and shown in Fig. 5. The band peak at $~ 3376$ $\mathrm{cm}^{-1}$ is the stretching band of $\mathrm{O}-\mathrm{H}$ and $\mathrm{N}-\mathrm{H}$, and the stretching vibration of $\mathrm{C}-\mathrm{H}$ was appeared at $\sim 2936$ $\mathrm{cm}^{-1}$ [48]. The peaks at $\sim 1654, \sim 1535$, and $\sim 1448$ $\mathrm{cm}^{-1}$ are ascribed to the $\mathrm{C}=\mathrm{O}$ stretching vibration of the
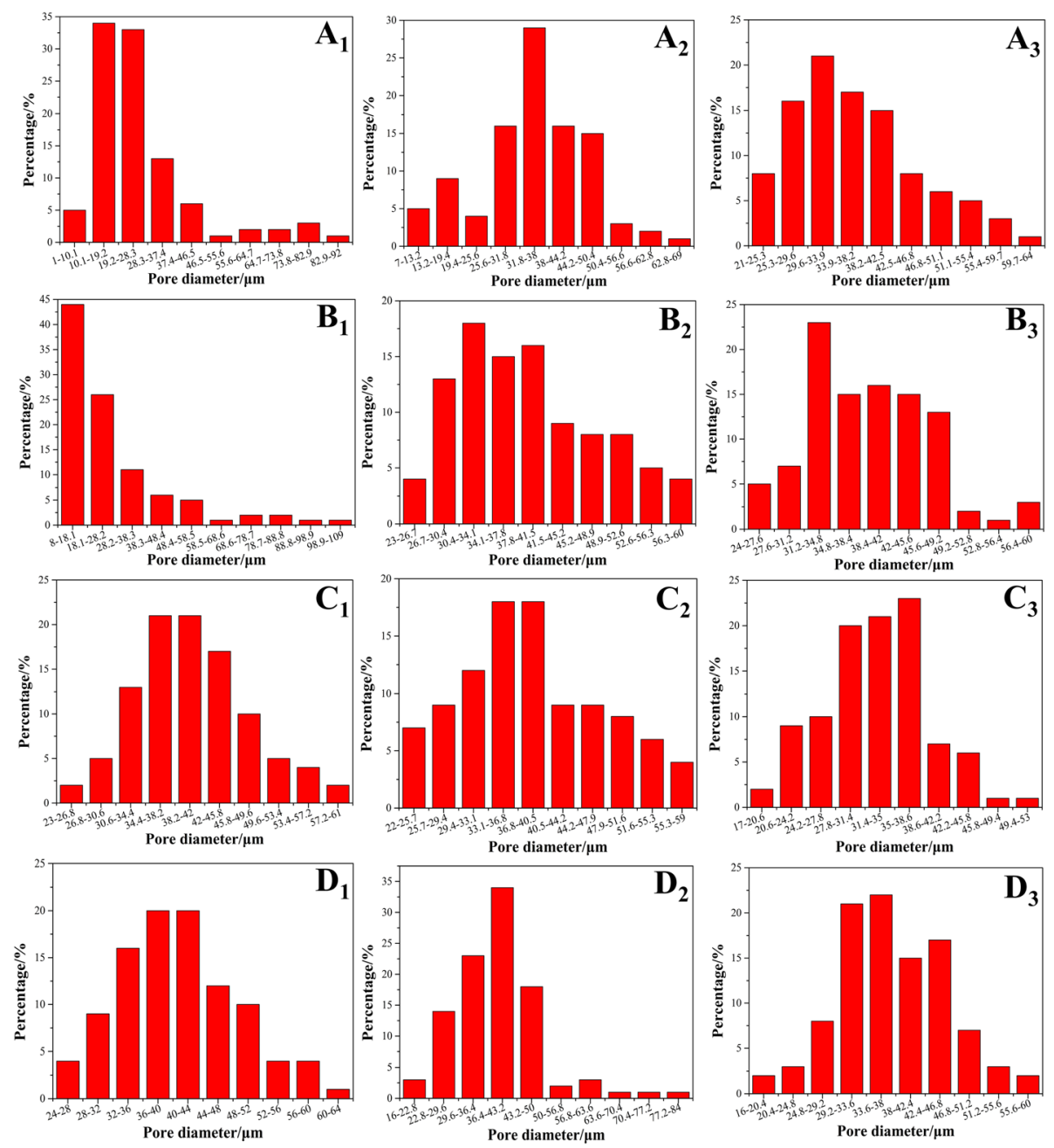

Fig. 4 Pore diameter distribution of $S A\left(A_{1}-D_{1}\right), S-V-2\left(A_{2}-D_{2}\right)$, and $V A\left(A_{3}-D_{3}\right)$ at different storage time 


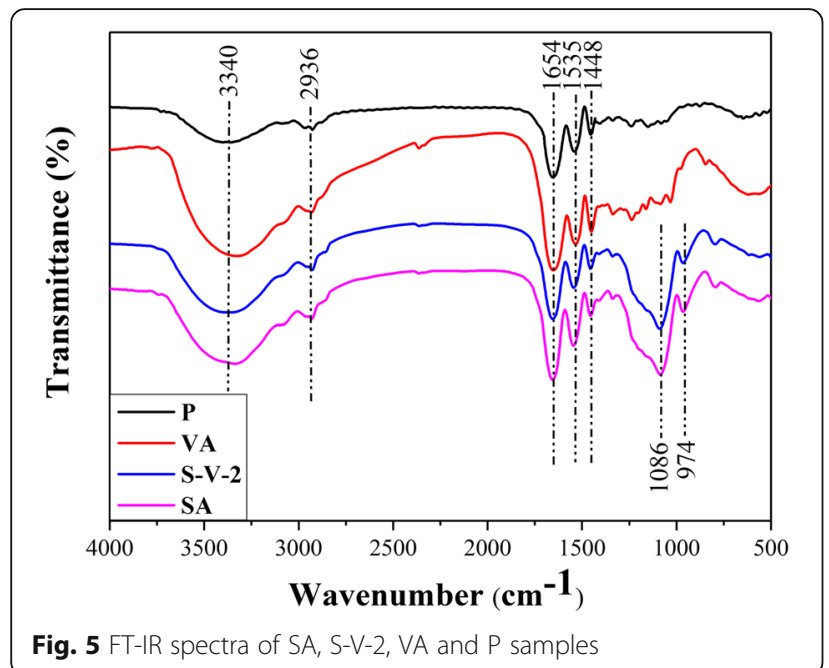

amide I band, $\mathrm{N}-\mathrm{H}$ bending vibration of the amide II band and C-N stretching vibration, respectively [49]. In addition, the new peaks appeared at $\sim 1086 \mathrm{~cm}^{-1}$ and $\sim$ $974 \mathrm{~cm}^{-1}$ are designated to the stretching vibration of $\mathrm{Si}-\mathrm{O}-\mathrm{Si}$ and $\mathrm{Si}-\mathrm{OH}$ in both SA and S-V-2 spectra, which identified that silicic acid was introduced into collagen fibers [20]. It is worth noting that the peaks of SA, S-V2 and VA at $3376 \mathrm{~cm}^{-1}$ are stronger and wider than those of pickled skin $(\mathrm{P})$, accompanied by a slight redshift. This phenomenon clearly may be attributed to the formation of hydrogen bonding between $\mathrm{Si}-\mathrm{OH}$ of silicic acid and/or phenolic hydroxyls of vegetable tanning agent with the amino groups of collagen fiber, which leads to decrease of the bond force constant of N-H, reduction of the electron density, and thus decrease of the vibration frequency [26]. In addition, it was discovered that no other crosslinking bonds appeared in S-V-2 except hydrogen bonds.

To gain more insight into the influence of vegetable tanning agents on chemical composition of silicic acid tanned leather, the elements $\mathrm{C}, \mathrm{N}, \mathrm{O}$, and $\mathrm{Si}$ of the SA and $\mathrm{S}-\mathrm{V}-2$ samples were characterized by $\mathrm{X}$-ray photoelectron spectroscopy (XPS), and the spectra was shown in Fig. 6. From the full spectrum (Fig. 6a), the nitrogen content in the SA (3.65\%) was similar to that in S-V-2 (3.16\%), however, the silicon content in SA $(10.40 \%)$ is much higher than that in S-V-2 (3.54\%), which is due to different amount of silicic acid added. Moreover, the content of oxygen in SA (36.19\%) is also higher than S$\mathrm{V}-2$ (29.66\%), which may be caused by the more $\mathrm{Si}-\mathrm{O}-\mathrm{Si}$ structure existing in the SA. On the contrary, C1s peak intensity of SA (49.77\%) is lower than that of S-V-2 (63.63\%). This may be the fact that there are more $\mathrm{C}$ elements in vegetable tanning agents. The peak fitting of the Si2p and O1s XPS spectra of SA and S-V-2 (Fig. 6be), showed that there was no visible difference in binding energy between them, indicating that no other bonding was formed in the combination-tanned leather [50]. Very

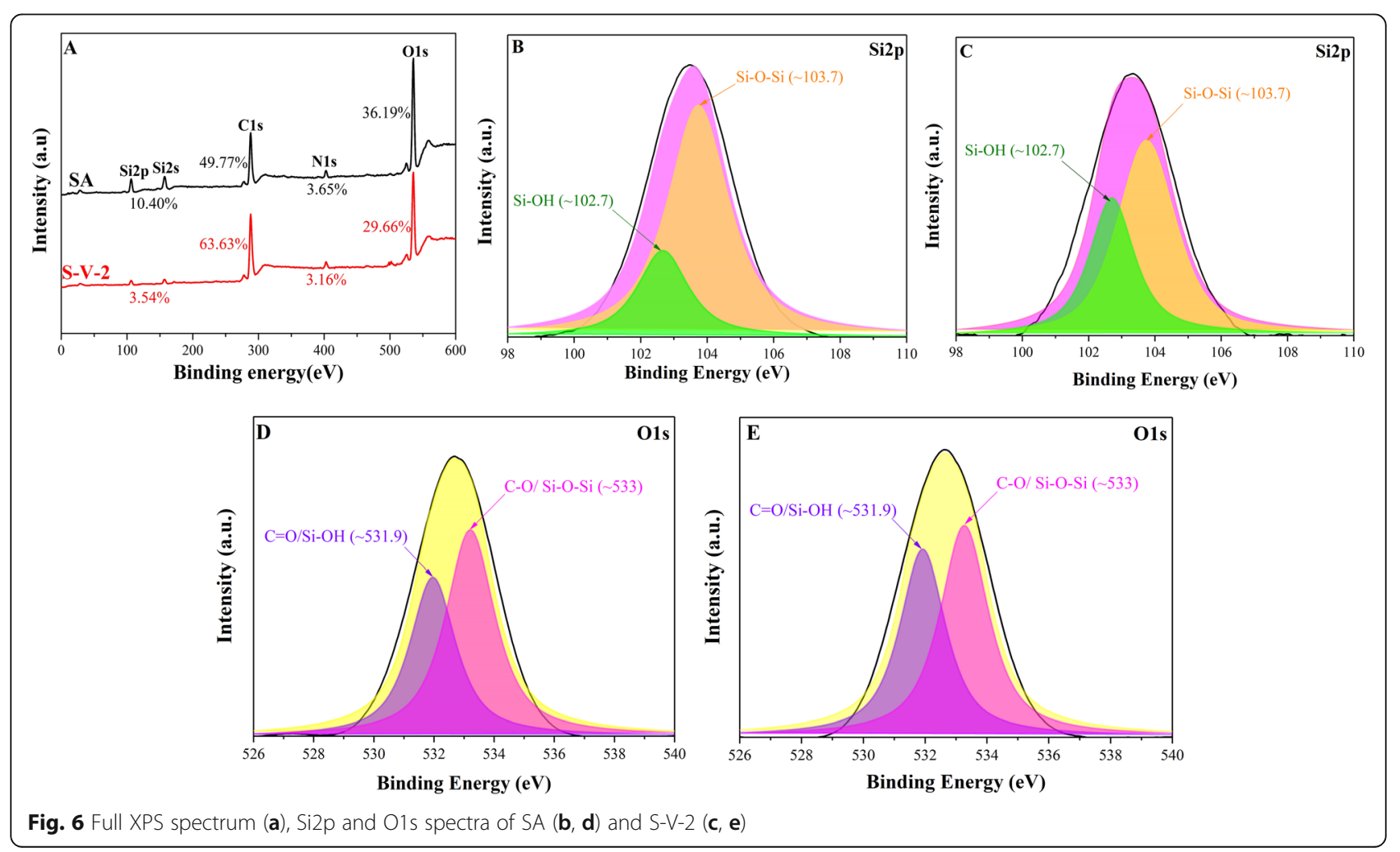


importantly, the relative content ratio of $\mathrm{Si}-\mathrm{OH}(\sim 102.7$ $\mathrm{eV})$ to $\mathrm{Si}-\mathrm{O}-\mathrm{Si}(\sim 103.7 \mathrm{eV})$ increased from 0.22 (Fig. 6b) to 0.60 (Fig. 6c), which may be due to the hydrogen bonding between phenolic hydroxyl groups and silicon hydroxyl groups inhibiting dehydration and condensation reaction between $\mathrm{Si}-\mathrm{OH}$ themselves, and thereby more $\mathrm{Si}-\mathrm{OH}$ groups remained $[51,52]$. This also can be supported by the change of energy level spectra of O1s (Fig. 6d-e). The O1s level spectra depicted the $\mathrm{C}=\mathrm{O} / \mathrm{Si}$ $\mathrm{OH} \quad(531.5-532.0 \mathrm{eV})$ and $\mathrm{C}-\mathrm{O} / \mathrm{Si}-\mathrm{O}-\mathrm{Si} \quad(\sim 533.0 \mathrm{eV})$ bond structures of SA and S-V-2 [53], of which the bond energy did not change obviously after adding vegetable tannin. Among them, the bonds $\mathrm{C}=\mathrm{O}$ and $\mathrm{C}-\mathrm{O}$ were mainly derived from collagen fibers, and thus there was no significant difference between the two leather samples. Nevertheless, the relative content ratio of $\mathrm{C}=\mathrm{O} / \mathrm{Si}$ $\mathrm{OH}$ to $\mathrm{C}-\mathrm{O} / \mathrm{Si}$-O-Si increased from 0.71 (Fig. $6 \mathrm{~d}$ ) to 0.84 (Fig. 6e). This demonstrated the fact that more amount of silicon hydroxyl groups was retained in the combination-tanned leather, which further suggested that the inhibition effect of plant polyphenol on condensation of $\mathrm{Si}-\mathrm{OH}$ themselves.

From the above discussion, it can be found that the addition of vegetable tanning agent improved the softness, hydrophilicity and storage stability of silicic acid tanned leather. In addition, the possible tanning mechanism of combination tanning was shown in Fig. 7 according to the FT-IR and XPS analysis results. On the one hand, silicic acid and vegetable tanning agent can form hydrogen bonds with the active groups of collagen

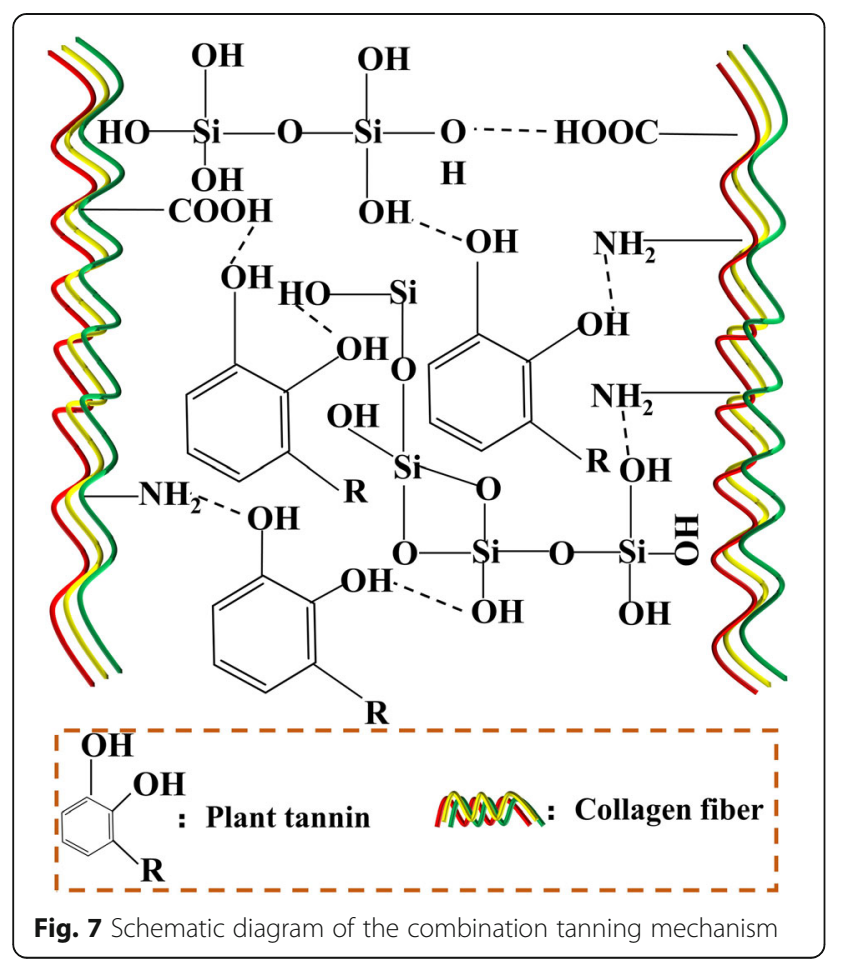

fibers, such as hydroxyl, carboxyl, amino groups, etc.; On the other hand, the condensation of $\mathrm{Si}-\mathrm{OH}$ groups and the hydrogen bonds formed between $\mathrm{Si}-\mathrm{OH}$ and phenolic hydroxyl groups increased the crosslinking degree of collagen fibers and effectively enhanced the tanning effect. More importantly, it should be noted that the hydrogen bonds formed between silicic acid and vegetable tanning agent inhabited the continuous condensation of $\mathrm{Si}-\mathrm{OH}$ between themselves, which is beneficial to improve the softness and hydrophilicity of leather.

\subsection{Waste water assessment}

Conventional test indicators, such as $\mathrm{BOD}_{5}, \mathrm{COD}$, TS, DS, and SS of the tannery wastewater, are main factors to evaluate the impact of tanning process on the environment [54]. Generally speaking, the higher of the value of $\mathrm{BOD}_{5} / \mathrm{COD}$, the easier the material is to biodegrade. When the $\mathrm{BOD}_{5} / \mathrm{COD}$ value is above 0.3 , it is implied that the waste water is well biodegradable, and may be disposed by bio-activated sludge [38]. From Table 4, it can be found that the value of $\mathrm{BOD}_{5} / \mathrm{COD}$ of the wastewater generated from tanning process of the SA, S-V-2 and VA leather samples are all higher than 0.3, which manifested the wastewater was easy to biodegrade and thus less effect on the environment [55]. It can be found that the TS, TDS, and TSS value of the combination tanning waste water is no more than that of the conventional chrome tanning process (32500-59,280, 27,000-54,500, 980-2440 mg/L) [55, 56], indicating an acceptable absorption of silicic acid and vegetable tanning agents. Moreover, this combination tanning method completely avoided the use of chrome tanning agent and other tanning materials with the risk of releasing free formaldehyde, thus meeting the requirements of green development of the leather industry. These findings provide a feasible direction for the development of cleaner tanning technology.

\section{Conclusions}

In this paper, a new and feasible chrome-free tanning method based on combination of silicic acid and plant tannins was established. The combination tanned leather was in possession of improved thermal stability, increased softness, acceptable hydrophilicity, appropriate micro-porous structure, and especially remarkable storage stability, due to the addition of vegetable tanning agent. It is worth noting that the leather obtained under the condition that mass ratio of silicic acid to vegetable tanning agent was 1:1 possessed the Ts value of above $80^{\circ} \mathrm{C}$ and outstanding comprehensive performances. Moreover, FT-IR and XPS analyses exhibited hydrogen bonding, that formed between silicon hydroxyl groups and phenolic hydroxyl groups, played an important role 
Table 4 Analysis results of tannery wastewater

\begin{tabular}{lllllll}
\hline Sample & BOD $_{\mathbf{5}}(\mathbf{m g} / \mathbf{L})$ & COD $(\mathbf{m g} / \mathbf{L})$ & BOD $_{\mathbf{5}} / \mathbf{C O D}$ & TS $(\mathbf{m g} / \mathbf{L})$ & TDS (mg/L) & TSS (mg/L) \\
\hline SA & $866 \pm 32$ & $2840 \pm 89$ & 0.305 & $42,056 \pm 3216$ & $40,272 \pm 2353$ & $1920 \pm 159$ \\
S-V-2 & $1210 \pm 56$ & $3680 \pm 109$ & 0.329 & $32,032 \pm 1679$ & $30,224 \pm 1253$ & $1508 \pm 142$ \\
VA & $1496 \pm 79$ & $4080 \pm 122$ & 0.367 & $21,928 \pm 167$ & $20,128 \pm 390$ & $1390 \pm 60$ \\
\hline
\end{tabular}

in the combination-tanning process and could inhibit the further condensation of $\mathrm{Si}-\mathrm{OH}$ themselves during the storage process. In addition, the environmental impact assessment by determining parameters such as $\mathrm{BOD}_{5} / \mathrm{COD}$, TS, DS and SS of the tanning wastewater revealed that this combination-tanning method was an environmentally benign chrome-free tanning technology. This research expands our knowledge of developing chrome-free tanning technology based on siliconcontaining materials, and would play a significant role in promoting cleaner leather production and sustainable development of the leather industry.

\begin{abstract}
Abbreviations
SEM: Scanning electron microscope; FT-IR: Fourier transform infrared spectroscopy; XPS: X-ray photoelectron spectroscopy; GPTMS: Silane glycidoxypropyltrimethoxysilane; Ts: Shrinkage temperature; DSC: Differential scanning calorimetry; TGA: Thermal gravimetric analysis; COD: Testing chemical oxygen demand; $\mathrm{BOD}_{5}$ : Five days' biological oxygen demand; TS: Total solids; TDS: Dissolved solids; TSS: Solid suspended; Tmax: Maximum thermal weight loss temperature; P: Pickled leather
\end{abstract}

\section{Supplementary Information}

The online version contains supplementary material available at https://doi. org/10.1186/s42825-021-00058-z.

\section{Additional file 1.}

\section{Acknowledgements}

Not applicable.

\section{Authors' contributions}

ZJ $L$ made substantial contributions to conception and design of this research, and critical revised the manuscript. ZT Z performed all the experiments and was a major contributor in data analyses and writing of this manuscript. $Y$ L, JC W, TL X, and LY S took part in the experiments about leather preparing process. And all authors have read and approved the final manuscript.

\section{Funding}

This research was supported by the National Natural Science Foundation of China (No. 21376153), the Fundamental Research Funds for the Central University of China, and Sichuan University-Zschimmer \& Schwarz CmbH \& Co. KG Scholarships (2020)

\section{Availability of data and materials}

All data generated or analysed during this study are included in this published article, and its supplementary information files.

\section{Declaration}

Competing interests

The authors declare no competing interest.
Received: 31 October 2020 Accepted: 12 April 2021

Published online: 15 July 2021

References

1. Baker I. Leather. In: Fifty materials that make the world. Cham: Springer; 2018.

2. Santos RJ, Agostini DLS, Cabrera FC, Budemberg ER, Job AE. Recycling leather waste: preparing and studying on the microstructure, mechanical, and rheological properties of leather waste/rubber composite. Polym Compos. 2015;36(12):2275-81. https://doi.org/10.1002/pc.23140.

3. Combalia F, Morera JM, Bartolí E. Study of several variables in the penetration stage of a vegetable tannage using ultrasound. J Clean Prod. 2016;125:314-9. https://doi.org/10.1016/j.jclepro.2016.03.099.

4. Bacardit A, Burgh S, Armengol J, Olle L. Evaluation of a new environment friendly tanning process. J Clean Prod. 2014;65:568-73. https://doi.org/10.1 016/j.jclepro.2013.09.052

5. Prokein M, Renner M, Weidner E, Heinen T. Low-chromium and lowsulphate emission leather tanning intensified by compressed carbon dioxide. Clean Techn Environ Policy. 2017;19(10):2455-65. https://doi.org/1 0.1007/s10098-017-1442-x.

6. Hedberg YS, Lidén C, Odnevall WI. Correlation between bulk- and surface chemistry of $\mathrm{Cr}$-tanned leather and the release of $\mathrm{Cr}(\mathrm{III})$ and $\mathrm{Cr}(\mathrm{VI})$. J Hazard Mater. 2014;280:654-61. https://doi.org/10.1016/j.jhazmat.2014.08. 061.

7. Sfaksi Z, Azzouz N, Abdelwahab A. Removal of $\mathrm{Cr}(\mathrm{VI})$ from water by cork waste. Arab J Chem. 2014;7(1):37-42. https://doi.org/10.1016/j.arabjc.2013.05. 031.

8. Zuriaga-Agusti E, Galiana-Aleixandre MV, Bes-Pia A, Mendoza-Roca JA, Risueno-Puchades $V$, Segarra V. Pollution reduction in an eco-friendly chrome-free tanning and evaluation of the biodegradation by composting of the tanned leather wastes. J Clean Prod. 2015;87:874-81. https://doi.org/1 0.1016/j.jclepro.2014.10.066

9. Hedberg YS. Chromium and leather: a review on the chemistry of relevance for allergic contact dermatitis to chromium. J Leather Sci Eng. 2020;2(1):20. https://doi.org/10.1186/s42825-020-00027-y.

10. Ariram N, Madhan B. Development of bio-acceptable leather using bagasse. J Clean Prod. 2020;250:119441. https://doi.org/10.1016/j.jclepro.2019.119441.

11. Covington A. Modern tanning chemistry. Chem Soc Rev. 1997;26(2):111-26. https://doi.org/10.1039/cs9972600111.

12. Brown EM, Dudley RL. Approach to a tanning mechanism: study of the interaction of aluminium sulfate with collagen. J Am Leather Chem Assoc. 2005;100(10):401-9.

13. Madhan B, Rao JR, Nair BU. Tanning agent based on mixed metal complexes of aluminum and zinc. J Am Leather Chem Assoc. 2001;96(9): 343-9.

14. Wei D, Xiaoyan P, Zhiwen D, Tsang DCW, Zhicheng J, Bi S. Constructing a robust chrome-free leather tanned by biomass-derived polyaldehyde via crosslinking with chitosan derivatives. J Hazard Mater. 2020;396:122771.

15. Yu Y, Wang Y, Ding W, Jianfei Z, Bi S. Preparation of highly-oxidized starch using hydrogen peroxide and its application as a novel ligand for zirconium tanning of leather. Carbohydrate Polymers. 2017:174:823-9.

16. Yu Y, Yanan W, Ding W, Jianfei Z, Bi S. Effect of catalyst on structure of hydrogen peroxide oxidized starch and its performance as a ligand in zirconium tanning of leather. Fine Chem. 2018;35:1928-34.

17. Liu Y, Chen Y, Yao J, Fan HJ, Shi B, Peng BY. An environmentally friendly leather-making process based on silica chemistry. J Am Leather Chem Assoc. 2010;105:84-93.

18. Shi JB, Wang $\mathrm{CH}, \mathrm{Hu}$ LY, Xiao YH, Lin W. Novel wet-white tanning approach based on laponite clay nanoparticles for reduced formaldehyde release and improved physical performances. ACS Sustain Chem Eng. 2019;7(1):1195201. https://doi.org/10.1021/acssuschemeng.8b04845. 
19. Li YP, Wang BC, Li ZJ, Li LX. Variation of pore structure of organosiliconemodified skin collagen matrix. J Appl Polym Sci. 2017;134:44831.

20. Zhang ZT, Liu J, Wang JC, Li ZJ. Insight into understanding incorporation of Glycidoxypropyltrimethoxysilane for improving hydrothermal stability and porous structure of silicic acid tanned leather. J Am Leather Chem Assoc. 2019;114:300-12.

21. Liao XP, Lu ZB, Shi B. Selective adsorption of vegetable tannins onto collagen fibers. Ind Eng Chem Res. 2003;42(14):3397-402. https://doi.org/1 0.1021/ie0209475

22. Musa AE, Gasmelseed GA. Combination tanning system for manufacture of shoe upper leathers: cleaner tanning process. I Soc Leather Technol Chem. 2012;96:239-45.

23. Fathima NN, Saravanabhavan S, Rao RJ, Nair BU. An eco-benign tanning system using aluminum, tannic acid, and silica combination. J Am Leather Chem Assoc. 2004:99:73-81.

24. Shi JB, Puig R, Sang J, Lin W. A comprehensive evaluation of physical and environmental performances for wet-white leather manufacture. J Clean Prod. 2016;139:1512-9. https://doi.org/10.1016/j.jclepro.2016.08.120.

25. Gil RR, Ruiz B, Lozano MS, Fuente E. The role of crosslinking treatment on the pore structure and water transmission of biocollagenic materials. J Appl Polym Sci. 2013;130(3):1812-22. https://doi.org/10.1002/app.39365.

26. Zhang ZT, Liu J, Gao WW, Sun LY, Li ZJ. Action of silicic acid derived from sodium silicate precursor toward improving performances of porous gelatin membrane. J Appl Polym Sci. 2020;137(30):48912. https://doi.org/10.1002/a pp.48912.

27. ISO 3380. Leather. Physical and mechanical tests. Determination of shrinkage temperature up to $100^{\circ} \mathrm{C}$. Geneva: International Organization for Standardization; 2015.

28. Madera TJ, Aguilar MJ, Márquez A, Vázquez F. Production of leather-like composites using chemically modified short leather fibers. I: chemical modification by emulsion polymerization. Polym Compos. 2004;23:49-60.

29. Zhang JW, Chen W, Gaidau C. Influence of microwave on chromium complex composition in tanning liquor. J Leather Sci Eng. 2020;2:1-11.

30. ISO 2419. Leather. Physical and mechanical tests. Sample preparation and conditioning. Geneva: International Organization for Standardization; 2012.

31. ISO 3376. Leather. Physical and mechanical tests. Determination of tensile strength and percentage extension. Geneva: International Organization for Standardization; 2020.

32. Qiang $T$, Chen $L$, Zhang $Q$, Liu XH. A sustainable and cleaner speedy tanning system based on condensed tannins catalyzed by laccase. J Clean Prod. 2018;197:1117-23. https://doi.org/10.1016/j.jclepro.2018.06.257.

33. ISO 2589. Leather-Physical and mechanical tests-Determination of thickness. Geneva: International Organization for Standardization; 2016.

34. Huang $W$, Song Y, Yu Y, Wang YN, Shi B. Interaction between retanning agents and wet white tanned by a novel bimetal complex tanning agent. J Leather Sci Eng. 2020;2:42825.

35. ISO 17235. Leather-Physical and mechanical tests-Determination of softness. Geneva: International Organization for Standardization; 2015.

36. Du WN, Zhang ZT, Fan WH, Gao WW, Su H, Li ZJ. Fabrication and evaluation of polydimethylsiloxane modified gelatin/silicone rubber asymmetric bilayer membrane with porous structure. Mater Des. 2018;158:28-38. https://doi. org/10.1016/j.matdes.2018.08.017.

37. Du WN, Dai GC, Wang BC, Li ZJ, Li LX. Biodegradable porous organosilicone-modified collagen fiber matrix: Synthesis and high oil absorbency. J Appl Polymer Sci. 2018;135:46264.

38. Gao DG, Cheng Y, Wang P, Li F, Qin J. An eco-friendly approach for leather manufacture based on $\mathrm{P}$ (POSS-MAA)-aluminum tanning agent combination tannage. J Clean Prod. 2020;257:120546. https://doi.org/10.101 6/j.jclepro.2020.120546.

39. Krishnamoorthy G, Sadulla S, Sehgal PK, Mandal AB. Greener approach to leather tanning process: $\mathrm{d}$-Lysine aldehyde as novel tanning agent for chrome-free tanning. J Cleaner Prod. 2013;42(mar.):277-86.

40. Wang YJ, Guo J, Chen H, Shan ZH. Influence of containing moisture on hydrothermal stability of modified collagen thermal characteristics analysis by DSC. J Therm Anal Calorim. 2010;99(1):295-300. https://doi.org/10.1007/ s10973-009-0561-y.

41. Su Q, Pu XM, Bai H, Chen XC, Liao XM, Huang ZB, et al. Improvement of Thermosensitive liposome stability by Cerasome forming lipid with Si-O-Si network structure. Curr Drug Deliv. 2018;15(4):585-93. https://doi.org/10.21 74/1567201814666170719111653.
42. Krishnamoorthy G, Ramamurthy G, Sadulla S, Sastry TP, Mandal AB. Click chemistry approach to conventional vegetable tanning process: accelerated method with improved organoleptic properties. Environ Sci Pollut Res Int. 2014;21(18):10678-85. https://doi.org/10.1007/s11356-014-3069-3.

43. Cucos A, Budrugeac P, Miu L. DMA and DSC studies of accelerated aged parchment and vegetable-tanned leather samples. Thermochim Acta. 2014; 583:86-93. https://doi.org/10.1016/j.tca.2014.03.022.

44. Li Y, Gao DG, Ma JZ, Lv B. Synthesis of vinyl polymer/ ZnO nano composite and its application in leather tanning agent. Mater Sci Forum. 2011;694:1037. https://doi.org/10.4028/www.scientific.net/MSF.694.103.

45. Sanchez G, Sanchez AF, Calderas L, Medina O, Manero A. Sodium montmorillonite effect on the morphology, thermal, flame retardant and mechanical properties of semi-finished leather. Appl Clay Sci. 2014;102:25460. https://doi.org/10.1016/j.clay.2014.10.007.

46. Ma JZ, Lv XJ, Gao DG, Li Y, Lv B, Zhang J. Nanocomposite-based green tanning process of suede leather to enhance chromium uptake. J Clean Prod. 2014;72:120-6. https://doi.org/10.1016/j.jclepro.2014.03.016.

47. Qiang XH, Ma LL, Yan Z, Zhang H. Preparation of comb-like amphiphilic styrene maleic anhydride copolymer derivatives and their modification to surface of chrome-tanned collagen Fiber. J Surfactant Deterg. 2013;16(3): 321-6. https://doi.org/10.1007/s11743-012-1410-8.

48. Wang XC, Guo XX, Zhang T, Wang HJ, Guo PY. Properties of polymers as a nanoscale material for fibers in leather. Fiber Polym. 2017;18(8):1504-11. https://doi.org/10.1007/s12221-017-6583-3.

49. Zhou Y, Ma J, Gao D, Li W, Shi J, Ren H. A novel chrome-free tanning approach based on sulfonated tetraphenyl calix 4 resorcinarene: preparation and application. J Clean Prod. 2018;201:668-77. https://doi.org/10.1016/j. jclepro.2018.07.196.

50. Kwon OM, See SJ, Kim SS, Hwang HY. Effects of surface treatment with coupling agents of PVDF-HFP fibers on the improvement of the adhesion characteristics on PDMS. Appl Surf Sci. 2014;321:378-86. https://doi.org/10.1 016/j.apsusc.2014.10.028.

51. Min CY, Huang YD, Liu L. Effect of nanosized ferric oxide on the thermostability of methylsilicone resin. J Mater Sci. 2007;42(20):8695-9. https://doi.org/10.1007/s10853-007-1761-0.

52. Yang XL, Zhao N, Zhou QZ, Wang Z, Duan CT, Cai C, et al. Facile preparation of hollow amino-functionalized organosilica microspheres by a template-free method. J Mater Chem. 2012;22(34):18010-7. https://doi.org/1 $0.1039 / \mathrm{c} 2 \mathrm{jm} 33220 \mathrm{e}$

53. Cai T, Wang R, Yang WJ, Lu S, Neoh KG, Kang ET. Multi-functionalization of poly (vinylidene fluoride) membranes via combined "grafting from" and "grafting to" approaches. Soft Matter. 2011;7(23):11133-43. https://doi.org/1 0.1039/c1sm06039b.

54. Wang XC, Yan Z, Liu XH, Qiang TT, Chen L, Guo PY, et al. An environmental polyurethane retanning agent with the function of reducing free formaldehyde in leather. J Clean Prod. 2019;207:679-88. https://doi.org/10.1 016/j.jclepro.2018.10.056

55. Wu XH, Qiang XH, Liu D, Yu LD, Wang XK. An eco-friendly tanning process to wet-white leather based on amino acids. J Cleaner Prod. 2020;270: 122399.

56. Yu D, Qiang XH, Cui L, Chen B, Wang XK, Wu XH. Preparation of a syntan containing active chlorine groups for chrome-free tanned leather. J Clean Prod. 2020;270:122351. https://doi.org/10.1016/j.jclepro.2020.122351.

\section{Publisher's Note}

Springer Nature remains neutral with regard to jurisdictional claims in published maps and institutional affiliations. 